SWEDISH SCHOOL OF ECONOMICS

AND BUSINESS ADMINISTRATION

THE YRJÖ JAHNSSON WORKING PAPER SERIES

IN INDUSTRIAL ECONOMICS

$3(2003)$

Thomas Gehrig \& Rune Stenbacka

DIFFERENTIATION-INDUCED SWITCHING COSTS

AND POACHING 
Differentiation-Induced Switching Costs and Poaching

Key words: product differentiation, poaching, endogenous switching costs, introductory price offers

JEL Classification: L13, L15, D43

(C) Swedish School of Economics and Business Administration

Thomas Gehrig \& Rune Stenbacka

Thomas Gehrig \& Rune Stenbacka

Swedish School of Economics and Business Administration

P.O.Box 479

00101 Helsinki, Finland

Distributor:

Library

Swedish School of Economics and Business Administration

P.O.Box 479

00101 Helsinki

Finland

Phone: +358-9-431 33 376, +358-9-431 33265

Fax: $\quad+358-9-43133425$

E-mail: publ@hanken.fi

http://www.hanken.fi/biblioteket/eng/page903.php

SHS intressebyrå IB (Oy Casa Security Ab), Helsingfors 2003

ISBN 951-555-780-1 


\title{
Differentiation-Induced Switching \\ Costs and Poaching ${ }^{*}$
}

\author{
Thomas Gehrig* $^{* *}$
}

and

Rune Stenbacka ${ }^{* * *}$

\section{July 2003}

\section{Abstract:}

We show that the presence of sufficiently significant switching costs, which are increasing in the degree of product differentiation, generates an equilibrium configuration with maximal differentiation within the framework of a Hotelling model with linear transportation costs. The equilibrium with maximal differentiation offers a formalization of the idea that competing firms have noncooperative incentives to establish maximal switching cost barriers. The equilibrium incentives for commitments to high switching costs can be explained with poaching profits, which are increasing in the switching costs. In fact, ex-ante competition for market shares in period 1 is unable to eliminate these poaching profits.

Keywords: product differentiation, poaching, endogenous switching costs, introductory price offers

JEL-classification: L13, L15, D43.

\footnotetext{
* We would like to thank $\mathrm{Oz}$ Shy for valuable comments. We gratefully acknowledge financial support from The Yrjö Jahnsson Foundation and the Deutsche Forschungsgemeinschaft.

** Institut zur Erforschung der Wirtschaftlichen Entwicklung, Universität Freiburg, D-79085 Freiburg, Germany and CEPR, London. E-mail: thomas.gehrig@,vwl.uni-freiburg.de

*** Corresponding author: Swedish School of Economics, P.O. Box 479, 00101 Helsinki, Finland. E-mail: Rune.Stenbacka@hanken.fi.
} 


\section{Introduction}

In a large class of important markets consumers face substantial switching costs. The switching costs experienced when shifting from one variety to a competing one might often be larger the higher the degree of differentiation between these products. For example, the learning costs associated with a switch from one software system to another one would reasonable be higher the more heterogeneous these systems are. In the present study we analyze how the presence of switching costs impacts on the equilibrium incentives for horizontal differentiation in a duopolistic industry. For that purpose we characterize the subgame perfect differentiation equilibrium within the framework of a two-period Hotelling model, where the consumers face switching costs which are are increasing as a function of the degree of product differentiation to which the firms have committed themselves. The equilibrium configuration with respect to product differentiation will, in fact, offer the basis for a characterization of endogenous switching costs in industry equilibrium.

From the literature we know that switching costs may affect price competition in two opposing ways: (1) If consumers are already locked-in, firms can raise prices knowing that consumers will not switch to a competing brand unless the price differential exceeds the barrier determined by the switching costs. (2) If consumers are not locked-in, brand-producing firms will compete intensively with introductory offers in order to create an installed base of customers, who will subsequently be locked-in with the technology. In fact, these two opposing effects create an interesting tradeoff, whereby the first effect captures the idea that switching costs dampen the efficiency-enhancing effects to (short-run) competition in markets, whereas the second effect characterizes the mechanism for how switching costs may intensify the (long-run) competition for markets.

Klemperer (1987b) explores implications of switching costs in the context of a 2-period Hotelling model where firms are unable to engage in intertemporal price discrimination and where the switching costs are measured by the proportion of customers who are completely locked-in by infinitely high switching costs. In such a context he demonstrates that an increase in the proportion of locked-in customers will induce higher equilibrium prices (in both periods) and thereby higher industry profits. However, if firms are able to price discriminate based on purchase histories, the equilibrium configuration will dramatically change. In fact, the development of the information technology has dramatically improved the ability of firms to 
condition prices on purchase histories (see Acquisti and Varian (2001) for convincing evidence). As shown in a two-period version of a Hotelling duopoly with intertemporal price discrimination, Gehrig and Stenbacka (2002) show that introductory offers will emerge in industries characterized by "large" switching costs. In fact, these authors demonstrate that endogenously determined discriminatory prices will generate market outcomes which are more competitive in the presence of lock-in effects than in their absence. Thus, intertemporal price discrimination generates a pricing profile characterized by introductory offers succeeded by a phase of exploitation of locked-in consumers, or "bargains-then-ripoffs", as also outlined in the simplified survey models of Varian (2003) or Farrell and Klemperer (2002).

Most of the existing literature on switching costs focus on environments where the consumers are homogenous, i.e. all consumers face the same switching costs, where these switching cost barriers are sufficiently large so as to rule out undercutting ${ }^{1}$, and where firms are unable to engage in poaching, i.e. induce customers of rival firms to switch by offering them special offers or discounts. It is, however, hard to defend all of these simplifications in light of empirical evidence. Shy (2002) emphasizes that customers are typically heterogeneous with respect to their switching costs and the consumer-specific switching costs are not observable for firms (or researchers). He empirically estimates switching costs in Finnish deposit markets and reports empirical regularities providing evidence of differentiation with respect to the switching costs facing depositors. A related study by Kim, Kliger and Vale (2003) presents Norwegian data in support of both substantial and differentiated switching costs in loan markets. In commenting on the switching costs associated with changing software Varian (2003) refers to a study which found that the total cost of installing an Enterprise Resource Planning (ERP) system such as SAP was up to eleven times greater than the purchase price of the software, reflecting organizationspecific costs of infrastructure upgrades, consultants, retraining programs etc.

Despite the existence of switching costs we do not observe complete brand loyalty on behalf of customers. Switching does seem to be an equilibrium phenomenon and often such brand switching is the result of poaching. ${ }^{2}$ In their important study of poaching, Fudenberg and Tirole (2000) refers to the U.S. market of long-distance telecommunication where for example $20 \%$ of the households changed operator in 1994 and where several operators were reported to offer one-

\footnotetext{
${ }^{1}$ Namely, there typically exists no Nash equilibrium in pure strategies unless the switching costs are so large so as to effectively create lock-in. In the absence of a Nash equilibrium in pure strategies researchers have typically directed attention to mixed strategy equilibria or to the concept of undercut-proof equilibrium (like in Shy $(2001,2002)$ ).

${ }^{2}$ Chen (1997) presents the first theoretical framework for the analysis of poaching in the presence of switching costs.
} 
time bonuses for switching to their services from a competitor in 1995-96. Another example can be picked from the competition between mobile phone operators in Finland. During a few days of heated competition between Radiolinja and Telia in June 2002, Radiolinja was reported by newspapers to have successively poached as much as $40 \%$ of Telia's customers with an aggressive introductory offer addressed to Telia's customers.

Intuitively, the presence of poaching makes the exploitation of locked-in customers harder. Thus, poaching could be expected to reduce the returns associated with the acquisition of an installed base through introductory offers. Consequently, it seems reasonable to ask the following question. Will the presence of poaching possibly eliminate the incentives to make introductory price offers and thereby qualitatively change the "bargains-then-ripoffs"-character of the intertemporal price structure? Is there actually any collective industry-wide incentive to create switching costs and what will be the optimal switching costs from an industry point of view?

Our study can also be viewed to offer an analysis of how the presence of switching costs impacts on the equilibrium incentives for horizontal product differentiation. The literature (see, for example, Anderson, de Palma and Thisse (1992)) focusing on the Hotelling model of product differentiation has established that there is generally no subgame perfect differentiation equilibrium with linear transportation costs. As shown by d'Aspremont, Gabszewicz and Thisse (1979) this picture changes dramatically if the Hotelling model is adjusted so as to capture quadratic transportation costs, because under such circumstances the subgame perfect differentiation equilibrium will be characterized by maximal differentiation. Our analysis demonstrates that the presence of sufficiently significant switching costs has a crucial impact on the subgame perfect differentiation equilibrium. With linear transportation costs the presence of sufficiently significant switching costs, which are increasing in the degree of differentiation, will guarantee the existence of a differentiation equilibrium and this will be characterized by maximal differentiation.

The paper is organized as follows. Section 2 presents the basic two-period model of horizontal differentiation with switching costs. In section 3 we characterize the equilibrium prices in period 2, whereas Section 4 presents the subgame perfect equilibrium prices in period 1. In section 5 we focus on the subgame perfect equilibrium configuration with respect to product differentiation, which endogenously generates the switching costs. Finally, concluding comments are found in section 6 . 


\section{A Model of Horizontal Differentiation with Switching Costs}

We consider a duopolistic industry where the firms produce horizontally differentiated goods. At the outset each firm commits to the horizontally differentiated product with which to compete in the market. The differentiation decision is captured by the firm's location on the unit interval in line with the traditional Hotelling model. The two brand-producing firms, A and B, are engaged in price competition with a horizon of two periods. The differentiated product is perishable and it must be re-purchased in period. Further, as we want to focus on true competition rather than the interaction between local monopolies we assume that the reservation value of the differentiated product is sufficiently high so as to eliminate the potential incentives of customers to withdraw from the market. We assume that the consumer needs to bear the transportation cost only once, in period 1. However, if the consumer switches to the rival in period 2 there is a switching cost.

In period 1 the brand-producing firms decide on the period- 1 prices, $p_{1}^{A}$ and $p_{1}^{B}$, in a noncooperative way. The consumer's brand selection in period 1 will create some degree of consumer-specific lock-in for later purchases. More precisely, we assume that a consumer has to incur an idiosyncratic switching cost $\mathrm{s}(\mathrm{i})(\mathrm{i}=\mathrm{A}, \mathrm{B})$ to break its period-1 customer relationship with firm $\mathrm{i}$ and switch to the competing supplier in period 2. Customers belonging to firm i's $(\mathrm{i}=\mathrm{A}, \mathrm{B})$ installed base are assumed to face differentiated switching costs drawn from a uniform distribution on $[0, \bar{s}]$. It seems, for example, reasonable to assume that consumers are heterogeneous with respect to the time required, and thereby the learning costs, associated with a switch from one operating system to a competing one. As another example, the costs of switching mobile phone operator (when this involves a change of phone number) might substantially differ across consumers as some might have substantial business-related activities associated with their connection, whereas others might have the connection for very limited leisure use. Additionally, we assume that in period 1 consumers know the distribution from which the switching costs are drawn, but the individual consumer is not aware of his/her idiosyncratic switching cost realization until period 2. Thus, the initial choice between suppliers is particularly simple as it cannot be conditioned on customer-specific switching costs.

We will assume that the shift from one brand to the rival one causes switching costs which are higher the more distant these products are relative to each other. Formally, we introduce the following assumption. 
Assumption 1 We assume that the consumers are uniformly distributed on the unit interval with a distribution which is stationary over periods and that all consumers buy one of the differentiated products in both periods. Let product $A(B)$ be located at a (b) $(0 \leq a, b \leq 1)$ with $a \leq b$. Then all the customers supplied by firm $A(B)$ in period 1 face switching costs which are uniformly distributed on the interval $[0, \sigma|b-a|]$ if they change supplier to $B(A)$ in period 2.

Intuitively, Assumption 1 captures the idea that switching costs are lower the more similar the differentiated varieties are. Furthermore, we can view $\sigma$ as a measure of the potential magnitude of the switching costs. Formally, $\sigma$ denotes the upper bound on how the degree of differentiation, the difference $|b-a|$, is translated into switching costs. In particular, the switching costs tend to disappear as $\sigma \rightarrow 0$. We can exemplify the relationship between product differentiation and switching costs with the banking industry. Bundling loans with other financial services represents one mechanism whereby lenders can create switching costs. If this is correct differentiation with respect to the bundles of financial services will affect the switching costs in such a way that the more heterogeneous these bundles are the higher are the switching costs.

In period 2 the firm can distinguish its own customers inherited from period 1 from those of the rival. Clearly, in the presence of switching costs established customer relationships create a strategic advantage in period 2. However, with customer recognition firms have an incentive to engage in price discrimination, poaching, with the intention of inducing the rival's customers to switch. Accordingly, in period 2 firm i will find it optimal to charge different prices to its own attached clients and those of the rival by announcing period-2 prices $\left(p_{2}^{i}, q_{2}^{i}\right), i=A, B$, respectively. We can make the interpretation of $q_{2}^{i}$ as a poaching price, whereby firm $i$ attempts to attract entrepreneurs belonging to its rival's period-1 clientele.

In fact, the development of the information technology has dramatically improved the ability of firms to condition prices on purchase histories (see, Acquisti and Varian (2001)). Recent studies by Villas-Boas $(1999,2001)$ have explored a number of interesting features of pricing dynamics in models with customer recognition. Chen (1997) and Fudenberg and Tirole (2000) have presented influential models exploring the implications of poaching as a 
phenomenon the sources of which are either driven by switching costs (Chen) or informationbased features (Fudenberg and Tirole).

Following the standard Hotelling model the production is assumed to take place at a constant marginal cost normalized to zero. Further, consumers are uniformly distributed on the unit interval and incur a constant proportional transportation cost $t>0$ per unit traveled. In each period they purchase at most one unit of the product, for which they will pay at most a price of $v>0$, which is their reservation price. Moreover, we assume that each consumer has, in principle, an incentive to buy at both locations, i.e. $v \geq t$. In other words, we exclude configurations with exclusively segmented markets as we want to focus on true competition and not simply on a segmented market with localized monopolies.

Both firms and consumers are assumed to evaluate future profits and consumption with a common discount factor. For simplicity, we normalise this discount factor to be one. Further, both types of agents, sellers and buyers, are rational and correctly anticipate the consequences of current actions on future decisions.

In summary, the market under consideration opens twice. At stage 1 firms compete for unattached consumers by announcing prices $p_{1}^{i}$. At stage 2 each firm announces prices $\left(p_{2}^{i}, q_{2}^{i}\right)$ to period-1 customers of its own and of its rival, respectively, and the attached customers decide whether they want to switch and pay the associated switching costs. At the end of the second period cash flows are realized and the market winds down.

In line with the general dynamic optimization principle of backward induction the proper solution concept for this two-stage game is the subgame perfect Nash equilibrium. We initially focus on characterizing the configuration of equilibrium prices in period 2. 


\section{Equilibrium Prices in Period 2 with Poaching}

In this section we solve for the equilibrium prices in period 2 . The period-2 prices have to be solved conditional on the customer histories and conditional on the configuration of market shares inherited from period 1. The individual histories are relevant because in period 2 firms want to price discriminate between their own captive customers and those of the rival. Hence, typically, the period-2 prices will depend on market shares inherited from period 1 . These market shares result from the period-1 prices, the determination of which we analyze in section 4 .

Let $0 \leq \mu^{i} \leq 1$ denote the market share acquired by firm $\mathrm{i}(i=A, B)$ in period 1 . These market shares, $\mu^{i}=\mu^{i}\left(p_{1}^{i}, p_{1}^{j}\right)$, represent the outcome of period-1 competition, and, are, hence, fixed for the determination of equilibrium in period 2.

The customers have already paid the transportation costs in period 1 , and for that reason the period-2 decision is based on the period 2 prices alone. However, the consumers take the potential switching costs into account. Incumbent customer relationships formed in period 1 are protected from competition up to the limit determined by the switching costs. Thus, customers will accept a poaching offer only if the poaching price undercuts the incumbent's quote by a sufficient margin so as to overcome the switching cost barrier. Analytically, a customer of firm i with switching cost $s(i)$ will switch to the rival, firm $\mathrm{j}$, if and only if $q_{2}^{j}+s(i)<p_{2}^{i}$. This condition immediately implies that poachers will always charge lower prices. Moreover, poaching will only attract consumers with sufficiently low switching costs, whereas incumbents can profit from charging higher prices to customers with less elastic demand due to sufficiently high switching costs. We denote by $\hat{s}(i)$ a period-1 customer of firm i indifferent between maintaining its customer relationship with firm $\mathrm{i}$ at price $p_{2}^{i}$ and switching to firm $\mathrm{j}$ offering the poaching price $q_{2}^{j}$. Formally, this critical consumer is defined by the condition $q_{2}^{j}+\hat{s}(i)=p_{2}^{i}$.

In the presence of consumers differentiated by their switching costs the existence of an equilibrium in pure strategies ${ }^{3}$ can be guaranteed. Technically, the continuous distributions of switching costs will eliminate such discontinuities of the reaction functions which could cause non-existence of price equilibria.

\footnotetext{
${ }^{3}$ Standard switching cost models typically impose a common level of switching costs for all customers. Such models, however, typically have no price equilibrium in pure strategies (see, for exmple Klemperer (1995)).
} 
In period 2 firm $i$ can profit from its incumbent customer relationship by $\mu^{i} p_{2}^{i} \int_{\hat{s}(i)}^{\sigma(b-a)} f^{i}(s(i)) d s(i)$, where the uniform distribution of the switching costs facing i's customers means that $f^{i}(s(i))=\frac{1}{\sigma(b-a)}$ on the support $[0, \sigma(b-a)]$. Moreover, firm $\mathrm{i}$ accumulates poaching profits from customers switching from $\mathrm{j}$ to $\mathrm{i}$ to the amount of $\mu^{j} q_{2}^{i} \int_{0}^{\hat{s}(j)} f(s(j)) d s(j)$, where now the uniform distribution of the switching costs facing $\mathrm{j}$ 's customers means that $f^{j}(s(j))=\frac{1}{\sigma(b-a)}$ on the support $[0, \sigma(b-a)]$. Thus, the total period-2 profits of firm i, consisting of the incumbency profits from an established relationship in period 1 and the poaching profits achieved in period 2, add up to:

$$
\Pi_{2}^{i}=\mu^{i} p_{2}^{i} \int_{\hat{s}(i)}^{\sigma(b-a)} f^{i}(s(i)) d s(i)+\mu^{j} q_{2}^{i} \int_{0}^{\hat{s}(j)} f^{j}(s(j)) d s(j) \quad, i, j=A, B, i \neq j,
$$

where $\hat{s}(i)=p_{2}^{i}-q_{2}^{j}$.

We can now make use of straightforward calculations to explicitly characterise the period2 equilibrium for firm $\mathrm{i}(\mathrm{i}, \mathrm{j}=\mathrm{A}, \mathrm{B}, i \neq j)$.

Proposition 1 (Period-2 Equilibrium Prices) There is a unique period-2 price equilibrium in pure strategies. This equilibrium is characterised by equilibrium prices $p_{2}^{i}=\frac{2}{3} \sigma(b-a)$ applied to customers in firm i's installed base as well as poaching prices $q_{2}^{i}=\frac{1}{3} \sigma(b-a)$ applied to customers of the rival firm. Customers with switching costs $s(i)<\hat{s}(i)=\frac{1}{3} \sigma(b-a)$ switch, whereas those with switching costs $s(i) \geq \hat{s}(i)=\frac{1}{3} \sigma(b-a)$ stay in the customer relationship formed with firm i in period 1.

Proof: See Appendix 
From Proposition 1 we can conclude that poaching takes place in equilibrium. In fact, with customers facing uniformly distributed switching costs the equilibrium poaching strategies will induce the proportion $1 / 3$ of the attached customers to switch.

Equilibrium prices are monotonic in the dispersion of the switching costs. More precisely, the equilibrium price charged to attached customers is proportional to the dispersion of the switching costs facing the firm's own clientele, whereas the poaching price is proportional to the dispersion of the switching costs facing the rival's attached customers. Furthermore, with symmetric switching costs $(s(i), s(j) \in U[0, \sigma(b-a)])$ the equilibrium price charged to incumbent customers is double relative to the poaching price. Moreover, the dispersion of the switching costs can also be viewed as a measure inversely related to the intensity of price competition. The more concentrated the distribution of switching cost, i.e. the lower the degree of differentiation of the switching costs, the higher is the intensity of period-2 competition and the lower are equilibrium profits in period 2.

From a methodological point of view it may be interesting to note that Proposition 1 provides an example where an equilibrium in pure strategies exists in the presence of switching costs. The literature ${ }^{4}$ largely concentrates on the case of a given level of switching costs common to all customers, which typically implies mixed strategies in equilibrium unless this common switching cost barrier is so high as to generate complete lock-in with no undercutting incentives. Contrary to such environments we have here demonstrated the existence of a unique pure strategy equilibrium as a consequence of unobserved ex ante differentiation across the switching costs facing different consumers.

Based on the equilibrium prices characterised in Proposition 1 the associated equilibrium profit in period 2 is given by

$$
\Pi_{2}^{i}\left(p_{1}^{i}, p_{1}^{j}\right)=\frac{1}{9}\left[\mu^{i} 4 \sigma(b-a)+\left(1-\mu^{i}\right) \sigma(b-a)\right], \quad i, j=A, B, i \neq j .
$$

The first component of (1), related to the dispersion of the switching costs facing the firm's attached customers, captures the equilibrium profits associated with the incumbent customer relationships formed in period 1. The second component of (1) denotes profits associated with the firm's poaching activities.

\footnotetext{
${ }^{4}$ See Klemperer (1995) for a survey.
} 
From (1) we can conclude that the equilibrium profits in period 2 are linear functions of period-1 market shares. This property is an implication of assuming a uniform distribution of switching costs. For general distributions the relationship between period-1 market shares and period 2 revenues will typically be more complex. Nevertheless, the result that each firm can secure a positive profit in period 2 independently of period- 1 market shares is a rather general one. By rewriting (1) according to

$$
\Pi_{2}^{i}=\frac{1}{9}\left[\mu^{i} 3 \sigma(b-a)+\sigma(b-a)\right]=\mu^{i} \Delta^{i}+\frac{1}{9} \sigma(b-a),
$$

where $\Delta^{i}=\frac{1}{3} \sigma(b-a)$ denotes the added value of establishing a customer relationship in period 1 rather than relying on the profits from poaching in period 2. This formulation shows that the period-2 profit is increasing in the firm's installed base in period 1 . This feature basically reflects that the profits associated with locked-in customers exceed those associated with poaching. This property with informational incumbency advantages relative to poaching profits affects competition for market shares in period 1. Furthermore, from the profit formulation above we can infer that the sensitivity of period-2 revenues to the installed customer base is reduced with increasing profitability of poaching. Further, each firm can secure the revenues it would earn, if it could poach the entire market in period 2. We can refer to the constant fraction of the period-2 profits, $\frac{1}{9} \sigma(b-a)$, as the reservation profit. Note that the reservation profit is generated by the period-2 poaching activity alone.

We summarize these features of the period-2 equilibrium profits in the following proposition.

\section{Proposition 2 (Properties of the Period-2 Equilibrium) The period-2 profits of firm $i$ are}

(a) increasing as a function of the dispersion of the switching costs facing its installed base of customers,

(b) increasing as a function of the dispersion of the switching costs facing its rival's customers,

(c) increasing in its installed base of customers.

We now proceed to analyse the price competition in stage 1. 


\section{Equilibrium Prices in Period 1}

How are the market shares $\mu^{A}$ and $\mu^{B}$ determined in stage 1? Rational consumers anticipate that the switching costs will limit their period-2 options, because the period-1 relationship will not be broken unless the poaching price from the rival firm undercuts the incumbent's price with a sufficiently large margin. The precise level of individual switching costs is not known initially, as we have assumed that the idiosyncratic switching costs are not realized until period 2. Hence the initial period-1 market shares will depend only on prices charged in period 1 and not on the precise level of switching costs. Thus, consumers strictly prefer lower period-1 prices. They are rational and forward-looking, however, to the extent that they know the statistical distribution of switching costs from which their own realization is drawn in period $2 .^{5}$

Hence, at the beginning of period 1 the horizontally differentiated firms compete for customers uniformly distributed at the unit interval and endowed with linear transportation costs with the cost parameter $t$.

The discounted intertemporal profit function for firm $\mathrm{i}$ is given by

$$
\Gamma^{i}\left(p_{1}^{i}, p_{1}^{j}\right)=\Pi_{1}^{i}\left(p_{1}^{i}, p_{1}^{j}\right)+\Pi_{2}^{i}\left(p_{1}^{i}, p_{1}^{j}\right) \quad, \quad i=A, B
$$

where the period-2 equilibrium profit was characterized in Proposition 2.

Applying standard methods associated with Hotelling competition in period 1 we can see that the address, $x_{1}$, of the consumer indifferent between product $\mathrm{A}$, located at a and offered at price $p_{1}^{A}$, and product $\mathrm{B}$, located at $\mathrm{b}$ and offered at price $p_{1}^{B}$, has to satisfy the equation

$$
\begin{aligned}
& p_{1}^{A}+\left|x_{1}-a\right| t+\frac{1}{\sigma(b-a)}\left[\int_{\hat{s}(A)}^{\sigma(b-a)} p_{2}^{A} d s(A)+\int_{0}^{\hat{s}(A)}\left(q_{2}^{B}+s(A)\right) d s(A)\right]= \\
& p_{1}^{B}+\left|b-x_{1}\right| t+\frac{1}{\sigma(b-a)}\left[\int_{\hat{s}(B)}^{\sigma(b-a)} p_{2}^{B} d s(B)+\int_{0}^{\hat{s}(B)}\left(q_{2}^{A}+s(B)\right) d s(B)\right] .
\end{aligned}
$$

Solving this equation we find the location of the indifferent consumer to be

\footnotetext{
5 Without this assumption consumers could be willing to pay slightly higher period-1 prices in order to benefit from poaching offers in period 2. Such strategic play is excluded when switching costs are not known in period 1 . This assumption largely simplifies the analysis without substantially changing results.
} 


$$
x_{1}=\frac{1}{2}(a+b)+\frac{p_{1}^{B}-p_{1}^{A}}{2 t} \text {. }
$$

Thus, from the general nature of the Hotelling model we can conclude that the market shares generated from the stage of period-1 competition are

$$
\mu^{A}\left(p_{1}^{A}, p_{1}^{B}\right)=\frac{1}{2}(a+b)+\frac{p_{1}^{B}-p_{1}^{A}}{2 t}
$$

and

$$
\mu^{B}\left(p_{1}^{B}, p_{1}^{A}\right)=1-\mu^{A}\left(p_{1}^{A}, p_{1}^{B}\right)
$$

for firm A and firm B, respectively. In light of (3a) and (3b) the period-1 profit functions can be expressed as

$$
\Pi_{1}^{i}\left(p_{1}^{i}, p_{1}^{j}\right)=p_{1}^{i} \mu^{i}\left(p_{1}^{i}, p_{1}^{j}\right)
$$

The discounted intertemporal profit functions (2) are linear in period-1 market shares and, consequently by (3a) or (3b), concave as functions of the period-1 price. More precisely, the period-1 prices are decided so as to solve the following maximization problems

$$
\max _{p_{1}^{i}} \mu^{i}\left(p_{1}^{i}, p_{1}^{j}\right)\left[p_{1}^{i}+\Delta^{i}\right]+\frac{1}{\sigma(b-a)} \int_{0}^{\hat{s}(j)} \mu^{j}\left(p_{1}^{j}, p_{1}^{i}\right) q_{2}^{i} d s(j), \quad i, j=A, B, i \neq j
$$

The optimization problems generate the two reaction functions

$$
(a+b) t+p_{1}^{j}-2 p_{1}^{i}-\Delta^{i}=0, \quad i, j=A, B, i \neq j
$$

Solving the system of equations determined by (6) we find the price equilibrium to be given by

$$
p_{1}^{A}=\frac{1}{3}(2+a+b) t-\Delta^{i}
$$




$$
p_{1}^{B}=\frac{1}{3}(4-a-b) t-\Delta^{j}
$$

where $\Delta^{i}=\Delta^{j}=\frac{1}{3} \sigma(b-a)$.

Consequently, we can formulate the following proposition.

Proposition 3 (Period-1 Equilibrium Prices) The subgame perfect period-1 prices are given by (7a) and (7b). These equilibrium prices exhibit a price discount relative to the static Hotelling equilibrium. This discount is proportional to the added value of establishing a customer relationship in period 1 rather than relying on the profits from poaching in period 2, which, in its turn, is proportional to the switching costs.

Proposition 4 characterizes the equilibrium pattern of pricing over time. The equilibrium pricing structure incorporates two phases: a phase of introductory offers succeeded by a phase of exploitation of locked-in customers. This pricing structure captures the basic idea that firms have incentives to compete very aggressively for customers in period 1 in order to acquire locked-in customers and these can subsequently be exploited in period 2 up to a limit determined by the switching costs.

From the period-1 equilibrium prices $(7 a)-(7 b)$ we can extract a number of interesting observations. Firstly, we can see that the period-1 prices converge to the equilibrium prices associated with a static Hotelling model in the absence of switching costs, i.e. if $\sigma \rightarrow 0$. Further, we can infer that the price-1 discount is higher the higher is the degree of product differentiation, as the switching costs are increasing as a function of product heterogeneity. What would happen if there were no differentiation in period 1, i.e. if there were homogenous Bertrand competition in period 1? In this case the equilibrium prices would be zero in each period and thereby industry profits would be zero. This is due to the feature that in our model the switching costs would disappear in the absence of product differentiation and with no switching costs the model would generate no phase of introductory offers.

With product differentiation the period-1 competition in prices may be so intense as to generate pricing below marginal costs in period 1. This will happen when the switching costs are 
sufficiently large relative to the transportation costs, i.e. when the ratio $\sigma / t$ is sufficiently large. Remember, that we have normalized marginal costs to be zero and, consequently, the formally negative prices should be interpreted to involve pricing below marginal costs, inducing negative period-1 profits. These negative period-1 profits have to be born by the period- 2 rents, which can be extracted from captive customers protected by switching costs.

Substituting the period-1 equilibrium prices (7a) and (7b) into (2) establishes that the firms' intertemporal two-period equilibrium profits are given by $(8 \mathrm{a})$ and $(8 \mathrm{~b})$ below:

$$
\begin{aligned}
\Gamma^{A} & =\frac{1}{18}\left[(2+a+b)^{2} t+\frac{1}{9} \sigma^{2}(b-a)^{2}\right] \\
\Gamma^{B} & =\frac{1}{18}\left[(4-a-b)^{2} t+\frac{1}{9} \sigma^{2}(b-a)^{2}\right] .
\end{aligned}
$$

The equilibrium profits (8a) and (8b) can be decomposed into profits associated with horizontal differentiation in period-1 and those associated with poaching activities in period- 2 . The additional rent which can be earned on locked-in customers in period 2 will actually be competed away through the phase of intensive price competition in period 1. In other words, competition for the formation of customer relationships will, in fact, be so intense as to exactly match, and thereby eliminate, the incumbency rents generated on locked-in customers within these relationships. However, the poaching profits survive the phase of intense price competition in period 1, because there are no credible mechanisms whereby firms would be able in period 1 to credible commit to future prices. Namely, if the firms were restricted to two-period binding commitments with respect to the prices, then ex ante competition among horizontally differentiated firms at period 1 would eliminate any two-period profits associated with switching costs.

We can conclude from (8a) and (8b) that higher switching costs will stimulate the poaching profits. This way an increased degree of product differentiation will add to the poaching profits. In a similar way an increase in the dispersion of the switching costs facing not only the firm's captive customers, but also in the switching costs facing customers of the rival, will stimulate the surviving poaching profits. Essentially, increasing heterogeneity among consumers reduces the intensity of period-2 competition and, thus, increases banks' period-2 profits. In particular, heterogeneity among customers of the rival promotes the poaching profit achievable in 
period 2. In light of (8a) and (8b) we can generally conclude that the oligopolists might have a collective interest in establishing maximal switching costs unless the costs for the creation of substantial switching costs are excessively high.

As the intertemporal equilibrium profits are functions of the switching costs facing consumers, our model lends itself to an explicit analysis of the firms' incentives to create switching costs. In particular, as these are closely tied to the degree of product differentiation our model can be applied to explore the equilibrium configuration of product differentiation. The next section will precisely focus on endogenous determination of switching costs through product differentiation.

\section{Endogenous Switching Costs and Product Differentiation}

In this section we will analyse the equilibrium configuration with respect to the horizontal differentiation decisions. This way we will be able generate endogenous switching costs within the framework of our model.

Differentiation of the $(8 a)$ and $(8 b)$ with respect to the differentiation decisions shows that

$$
\begin{aligned}
& \frac{\partial \Gamma^{A}}{\partial a}=\frac{1}{18}\left[2 t(2+a+b)-4 \sigma^{2}(b-a)\right] \\
& \frac{\partial \Gamma^{B}}{\partial b}=\frac{1}{18}\left[-2 t(4-a-b)+4 \sigma^{2}(b-a)\right],
\end{aligned}
$$

respectively. Differentiating once more we find that

$\frac{\partial^{2} \Gamma^{A}}{\partial a^{2}}=\frac{1}{18}\left[2 t+4 \sigma^{2}\right]>0$ and $\frac{\partial^{2} \Gamma^{B}}{\partial b^{2}}=\frac{1}{18}\left[2 t+4 \sigma^{2}\right]>0$.

Consequently, the intertemporal profit functions are convex with respect to the differentiation parameters. As minimal differentiation $(a=b)$ unambiguously yields zero profits we can conclude that maximal differentiation must represent the equilibrium configuration. Thus, we can formulate the following 
Proposition 4 (Maximal Differentiation with Switching Costs) The subgame perfect equilibrium exhibits maximal product differentiation $(a=0$ and $b=1)$ if the consumers face switching costs which are drawn from a non-empty uniform distribution, i.e. $U[0, \sigma(b-a)]$, with the upper switching cost bound sufficiently large, more precisely $\sigma>\sqrt{5 t / 2}$, relative to the transportation costs.

Proof: See Appendix.

It can easily be verified that maximal differentiation will yield equilibrium payoffs $\Gamma^{i}=\frac{t}{2}+\frac{\sigma^{2}}{9}$ for both firms. These payoffs represent the sum of two distinguishable components: the static Hotelling payoff with firm locations at the endpoints of the unit interval, $t / 2$, and the poaching profits, $\sigma^{2} / 9$, which are increasing in the dispersion of the distribution of the customers' switching costs.

In the literature (as extensively covered in, for example, Anderson, de Palma and Thisse (1992)) dealing with the Hotelling model of product differentiation it has been shown that there is generally no subgame perfect differentiation equilibrium with linear transportation costs. This picture changes dramatically if the Hotelling model is adjusted so as to capture quadratic transportation costs. As shown by d'Aspremont, Gabszewicz and Thisse (1979), the subgame perfect differentiation equilibrium will be characterized by maximal differentiation if there are quadratic transportation costs. Our analysis shows that the presence of sufficiently significant switching costs has a crucial impact on the subgame perfect differentiation equilibrium. With linear transportation costs the presence of sufficiently significant switching costs growing in the degree of differentiation will guarantee the existence of a differentiation equilibrium and this will be characterized by maximal differentiation.

Intuitively, in our model the presence of switching costs, which are increasing in the degree of differentiation, adds to the returns from increased differentiation on top of the wellknown effect of relaxed price competition from increased differentiation. In our model an increased degree of product differentiation is a device to shift the distribution of switching costs towards higher levels. The return from added differentiation will be sufficient so as to generate maximal differentiation when the parameter $\sigma$ is sufficiently large in relationship with the transportation cost parameter t. This condition means that the distribution of switching costs is 
shifted to sufficiently high levels. Under these conditions an increased degree of differentiation in turn stimulates the poaching profits, and thereby industry profits. The irreversible differentiation decisions represent a noncooperative strategic device whereby the firms can raise the switching costs to the collective benefit of the industry.

The characterization of the differentiation equilibrium actually makes the switching costs, or more precisely their distribution, endogenous. As far as we know, the existing literature on switching costs has typically been restricted to situations where these costs are exogenously given. In this respect our principle of maximal differentiation offers a formalization of the idea that competing firms have an incentive to establish switching costs which are as high as possible. It should be emphasized that this conclusion is far from self-evident, because within the twoperiod framework high switching cost barriers will also induce a phase of intense competition for market shares in period 1. In fact, in our model the equilibrium incentives for commitments to high switching costs can be explained with reference to the poaching profits. The poaching profits are increasing as a function of the switching costs and these profits cannot be eliminated through intense competition in phase 1 .

\section{Concluding Comments}

Our analysis has established that the presence of sufficiently significant switching costs, which are increasing as a function of the degree of product differentiation, will generate an equilibrium configuration with maximal differentiation within the framework of a Hotelling model with linear transportation costs. Thus, the presence of switching costs makes a decisive difference, because with linear transportation costs the Hotelling model has no subgame perfect differentiation equilibrium in the absence of these switching costs.

In our model the differentiation equilibrium represents the mechanism which makes the switching costs endogenous. The equilibrium with maximal differentiation offers a formalization of the idea that competing firms have noncooperative incentives to establish switching cost barriers which are as high as possible. This conclusion is remarkable, because within the considered two-period framework high switching cost barriers will also induce a phase of intense competition for market shares in period 1. In fact, in our model the equilibrium incentives for commitments to high switching costs can be explained with reference to the poaching profits, which are increasing as a function of the switching costs. In fact, the phase of ex-ante competition 
for market shares in period 1 is unable to eliminate these poaching profits as long as firms are unable to credibly commit to future prices.

\section{Appendix}

\section{Proof of Proposition 1:}

The proof is constructive. Consider the segment of consumers served by firm A in period 1 . The market share if these customers is measured by $\mu^{A}$. In period 2 firm A can exploit its incumbency advantage by holding on to those customers who are equipped with high switching costs. The profits associated with this market segment are affected by A's choice of $p_{2}^{A}$, whereas $q_{2}^{A}$ affects the poaching revenues earned from inducing customers belonging to B's installed base to switch. In order to determine $p_{2}^{A}$ firm A solves:

$$
\max _{p_{2}^{A}} \mu^{A} p_{2}^{A} \frac{1}{\sigma(b-a)} \int_{\hat{s}(A)}^{\sigma(b-a)} d s(A) .
$$

Firm B attempts to attract the customers with low switching costs in the pool of A's installed base by offering a poaching price $q_{2}^{B}$. Hence, firm B solves

$$
\max _{q_{2}^{B}} \quad \mu^{A} \frac{1}{\sigma(b-a)} \int_{0}^{\hat{s}(A)} d s(A) .
$$

The reaction functions (first order conditions) generated by these optimization problems can be written as

$$
\left(\begin{array}{cc}
2 & -1 \\
-1 & 2
\end{array}\right)\left(\begin{array}{l}
p_{2}^{A} \\
q_{2}^{B}
\end{array}\right)=\left(\begin{array}{c}
\sigma(b-a) \\
0
\end{array}\right)
$$

Accordingly, the equilibrium prices in period 2 are uniquely determined by

$$
\left(\begin{array}{l}
p_{2}^{A} \\
q_{2}^{B}
\end{array}\right)=\frac{1}{3}\left(\begin{array}{c}
2 \sigma(b-a) \\
\sigma(b-a)
\end{array}\right) .
$$


The argument for the remaining $\mu^{B}=1-\mu^{A}$ consumers runs completely analogously and determines $q_{2}^{A}$ and $p_{2}^{B}$ in the way characterized by Proposition 1 .

Furthermore, applying standard calculus it can be verified that the sufficient second-order conditions are satisfied because

$$
\begin{aligned}
& \frac{\partial^{2} \Pi_{2}^{i}}{\partial p_{2}^{i^{2}}}<0, \frac{\partial^{2} \Pi_{2}^{i}}{\partial q_{2}^{i^{2}}}<0 \text { and } \frac{\partial^{2} \Pi_{2}^{i}}{\partial p_{2}^{i^{2}}} \frac{\partial^{2} \Pi_{2}^{i}}{\partial q_{2}^{i^{2}}}-\frac{\partial^{2} \Pi_{2}^{i}}{\partial p_{2}^{i} \partial q_{2}^{i}} \frac{\partial^{2} \Pi_{2}^{i}}{\partial p_{2}^{i} \partial q_{2}^{i}}>0 \\
& (\mathrm{i}, \mathrm{j}=\mathrm{A}, \mathrm{B}, i \neq j) .
\end{aligned}
$$

\section{Q.E.D.}

\section{Proof of Proposition 6:}

The convexity of the intertemporal profit functions was already shown in (9). Hence, in order to establish maximal differentiation as a subgame perfect equilibrium we have to make sure that $\left.\frac{\partial \Gamma^{A}}{\partial a}\right|_{a=0}<0$ and $\left.\frac{\partial \Gamma^{B}}{\partial b}\right|_{b=1}>0$.

We first establish a sufficient condition for $\left.\frac{\partial \Gamma^{A}}{\partial a}\right|_{a=0}<0$. Substituting $a=0$ into A's reaction function we can directly see that $\left.\frac{\partial \Gamma^{A}}{\partial a}\right|_{a=0}<0$ if and only if $\frac{b}{2+b}<\frac{\sigma^{2}}{t}$. Because the function $g(b)=\frac{b}{2+b}$ is an increasing function of $b$ we can conclude that $\sigma^{2}>t / 3$ constitutes a sufficient condition for the inequality $\left.\frac{\partial \Gamma^{A}}{\partial a}\right|_{a=0}<0$ to hold.

We next characterize a sufficient condition for $\left.\frac{\partial \Gamma^{B}}{\partial b}\right|_{b=1}>0$. Substituting $b=1$ into B's reaction function we can directly see that $\left.\frac{\partial \Gamma^{B}}{\partial b}\right|_{b=1}>0$ if and only if $\frac{3-a}{2(1-a)}<\frac{\sigma^{2}}{t}$. Since the function $h(a)=\frac{3-a}{2(1-a)}$ is an increasing function of a it follows that $\sigma^{2}>5 t / 2$ is a sufficient condition for the condition $\left.\frac{\partial \Gamma^{B}}{\partial b}\right|_{b=1}>0$ to hold. Consequently, $\sigma^{2}>5 t / 2$ 
represents a sufficient condition for both inequalities $\left.\frac{\partial \Gamma^{A}}{\partial a}\right|_{a=0}<0$ and $\left.\frac{\partial \Gamma^{B}}{\partial b}\right|_{b=1}>0$ to hold.

For differentiation configurations sufficiently close to minimal differentiation with $a=b=1 / 2$ there might not exist any differentiation equilibrium in pure strategies. Potential eqquilibria in mixed strategies in this range will yield expected payoffs far below those associated with maximal differentiation.

\section{Q.E.D.}

\section{References}

Acquisti, A. and H. Varian, (2001), "Conditioning Prices on Purchase History," working paper, University of California, Berkeley.

Anderson, S., de Palma A. and J.-F. Thisse, (1992), Discrete Choice Theory of Product Differentiation. MIT Press, Cambridge (MA).

Chen, Y., (1997), "Paying Customers to Switch," Journal of Economics and Management Strategy, 6, 877-897.

d'Aspremont, C., Gabszewicz, and J.-F. Thisse, (1979), “On Hotelling's Stability in Competition," Econometrica, 47, 1145-1150.

Farrell, J. and P. Klemperer, (2002), "Coordination and Lock-In: Competition with Switching Costs and Network Effects," Chapter prepared for Handbook of Industrial Organization, Vol. 3.

Fudenberg, D. and J. Tirole, (2000), "Customer Poaching and Brand Switching," RAND Journal of Economics, 31, 634-657.

Gehrig, T. and R. Stenbacka, (2002), "Introductory Offers in a Model of Strategic Competition," Centre for Economic Policy Research (CEPR) Discussion Paper \# 3189.

Kim, M., D. Kliger and B.Vale, (2003), "Estimating Switching Costs: The Case of Banking," Journal of Financial Intermediation, 12, 25-56.

Klemperer, P., (1987a), "Markets with Consumer Switching Costs," Quarterly Journal of Economics, Vol. 102, No. 2., pp. 375-394. 
Klemperer, P., (1987b), "The Competitiveness of Markets with Switching Costs," RAND Journal of Economics 18, 138-150.

Klemperer, P., (1995), "Competition when Consumers have Switching Costs: An Overview with Applications to Industrial Organization, Macroeconomics, and International Trade," Review of Economic Studies 62, 515-539.

Shy. O., (2001), The Economics of Network Industries. Cambridge University Press, Cambridge, United Kingdom.

Shy, O., (2002), “A Quick-and-Easy Method for Estimating Switching Costs,” International Journal of Industrial Organization 20, 71-87.

Varian, H., (2003), "Economics of Information Technology," working paper, University of California, Berkeley.

Villas-Boas, M., (1999), "Dynamic Competition with Customer Recognition," RAND Journal of Economics, 30, 604-631.

Villas-Boas, M., (2001), "Price Cycles in Markets with Customer Recognition," working paper, University of California, Berkeley. 
The Yrjö Jahnsson Working Paper Series in Industrial Economics is funded by The Yrjö Jahnsson Foundation.

\section{Editor of the Working Paper Series: Professor Rune Stenbacka}

1. Anthony Dukes \& Esther Gal-Or: Negotiations and Exclusivity Contracts for Advertising

2. Oz Shy \& Rune Stenbacka: Partial Subcontracting, Monitoring Cost, and Market Structure

3. Jukka Liikanen, Paul Stoneman \& Otto Toivanen: Intergenerational Effects in the Diffusion of New Technology: The Case of Mobile

1. Thomas Gehrig \& Rune Stenbacka: Introductory Offers in a Model of Strategic Competition

2. Amit Gayer \& Oz Shy: Copyright Protection and Hardware Taxation

3. Christian Schultz: Transparency and Tacit Collusion in a Differentiated Market

4. Luis H. R. Alvarez \& Rune Stenbacka: Strategic Adoption of Intermediate Technologies: A Real Options Approach

5. Thomas Gehrig \& Rune Stenbacka: Information Sharing in Banking: An Anti-Competitive Device?

6. Oz Shy \& Rune Stenbacka: Regulated Business Hours, Competition, and Labor Unions

7. Jean Jacques-Laffont, Scott Marcus, Patrick Rey \& Jean Tirole: Internet Interconnection and The Off-Net-Cost Pricing Principle

8. Marc Ivaldi \& Frank Verboven: Quantifying the Effects from Horizontal Mergers in European Competition Policy

9. Ari Hyytinen \& Otto Toivanen: Do Financial Constraints Hold Back Innovation and Growth? Evidence on the Role of Public Policy

10. Staffan Ringbom\& Oz Shy: Advance Booking, Reservations and Refunds

1. Luis H. R. Alvarez \& Rune Stenbacka: Irreversibility, Uncertainty and Investment in the Presence of Technological Progress

2. Thomas Gehrig \& Rune Stenbacka: Screening Cycles

3. Thomas Gehrig \& Rune Stenbacka: Differentiation-Induced Switching Costs and Poaching 